\title{
Physical Therapy Management in Femoral Ollier Disease
}

\author{
Ida Ayu Made Pradnyanini ${ }^{1 *}$, I Putu Gde Surya Adhitya ${ }^{2}$
}

'Bachelor and Professional Program of Physical Therapy, College of Medicine, Universitas Udayana

2Department of Physical Therapy, College of Medicine, Universitas Udayana

*Corresponding author: Ida Ayu Made Pradnyanini; Bachelor and Professional Program of Physical Therapy, College of Medicine, Universitas Udayana; idanini97@gmail.com
Received : 2020-01-20 Accepted : 2020-03-26 Published: 2020-05-15

\section{INTRODUCTION}

Ollier disease (OD) is a non-hereditary, an uncommon bone disorder of endochondral ossification. ${ }^{1}$ In 1897, the first case of OD was described by Louis Xavier Edouard Léopold Ollier in the Lyon Surgical Society meeting. At that time, Ollier presented a child patient with characteristics of multiple swellings in the fingers and deformity to the bones of radius, ulna, and tibia. ${ }^{2}$ Then, he described another child patient with OD that mostly affected the long bones. ${ }^{3}$

The ratio of OD is 1 per 100,000 persons in a population. ${ }^{4}$ Some characteristics of OD are persisting cartilage masses in the diaphysis and metaphysis parts of the bone, and usually asymmetric of the limbs. Further, the progression of OD causes the affected bone to be an irregular deforming or shortening. In childhood enchondromas associated with OD start out as benign which subject to pathological fractures, they may become cancerous (malignant) in adult life. ${ }^{5}$ When OD develops aggressively, a high risk for cancers acquired, namely chondrosarcomas, ovarian carcinoma, and hepatocellular carcinoma. ${ }^{6,7}$

OD is diagnosed by radiographic assessment, which known as type I of enchondromatoses, and the types II, III, IV, V, and VI are known as Maffucci syndrome, metachondromatosis, spondyloenchondrodysplasia, enchondromatosis,
Further, the patient has been undergone surgical intervention for the tibial enchondromatosis. Physical therapy management aimed to improve the range of motion, pain, gait pattern, and activity of daily living. After three sessions of intervention, the patient reported the improvement in the pain and range of motion of the right lower limb.

Conclusion: The physical therapy management might improve the pain and lower limb range of motion after the surgical intervention in femoral OD.

Keywords: Ollier disease, enchondromatosis, physical therapy

Cite this Article: Pradnyani, I.A.M., Adhitya, I.P.G.S. 2020. Physical Therapy Management in Femoral Ollier Disease. Physical Therapy Journal of Indonesia 1(1): 1-4.

and cheirospondyloenchondromatosis, respectively. ${ }^{8}$ The surgical intervention is generally used to treat $\mathrm{OD}$, although the evolution was often benign but because of considering the high number of lesions by malignant evolution cases.9

Currently, the management of physical therapy in the treatment of OD is uncertain. Lack of published literature in the physical therapy area regarding OD could be a factor of the difficulty of the physical therapy practitioner to make a treatment decision to OD patients after receiving surgical treatment. The purpose of this paper was to describe an OD case and physical therapy management following the surgical intervention, especially in the femoral bone. The patient had permitted to use this clinical case as a report.

\section{CASE REPORT}

A patient of 8-year-old girl is an elementary school student diagnosed with Ollier disease through the standard medical assessments. She is the first child of two siblings, where the family history of having the same disease was denied. Initially, the patient felt down suddenly when playing with her friends at the age of 3 years, then felt severe pain on the limbs at that time. She had taken the traditional masseur to deal with the condition because of lack of information since she and her family lived in away from the city. Then, there was no improvement for 
the pain, instead of the lumps appear on both hands and right legs that enlarge over time. The patient went to the hospital for radiological examinations in 2016 (Figure 1). The patient received surgical intervention of tibia bone lengthening using the external fixation on 9 September 2018. After five months, the external fixation date on the tibial bone was release. The recent condition, the patient underwent the surgical of bone lengthening on the right femur bone on 29 April 2019.

One day after surgery, the physical therapist inspected the general condition of the patient limbs, while assessed the pain level and range of motions of the surgical area and the right leg, respectively. The visible lumps of mass and palpable swelling on both upper arms and deformity on the right wrist towards the ulnar deviation position appeared on the upper extremities. On the lower extremities, the external fixation attached to the skin of tight, wrapped of leg by elastic bandage, surgical scars on the right foot, leaning to plantar flexion of the

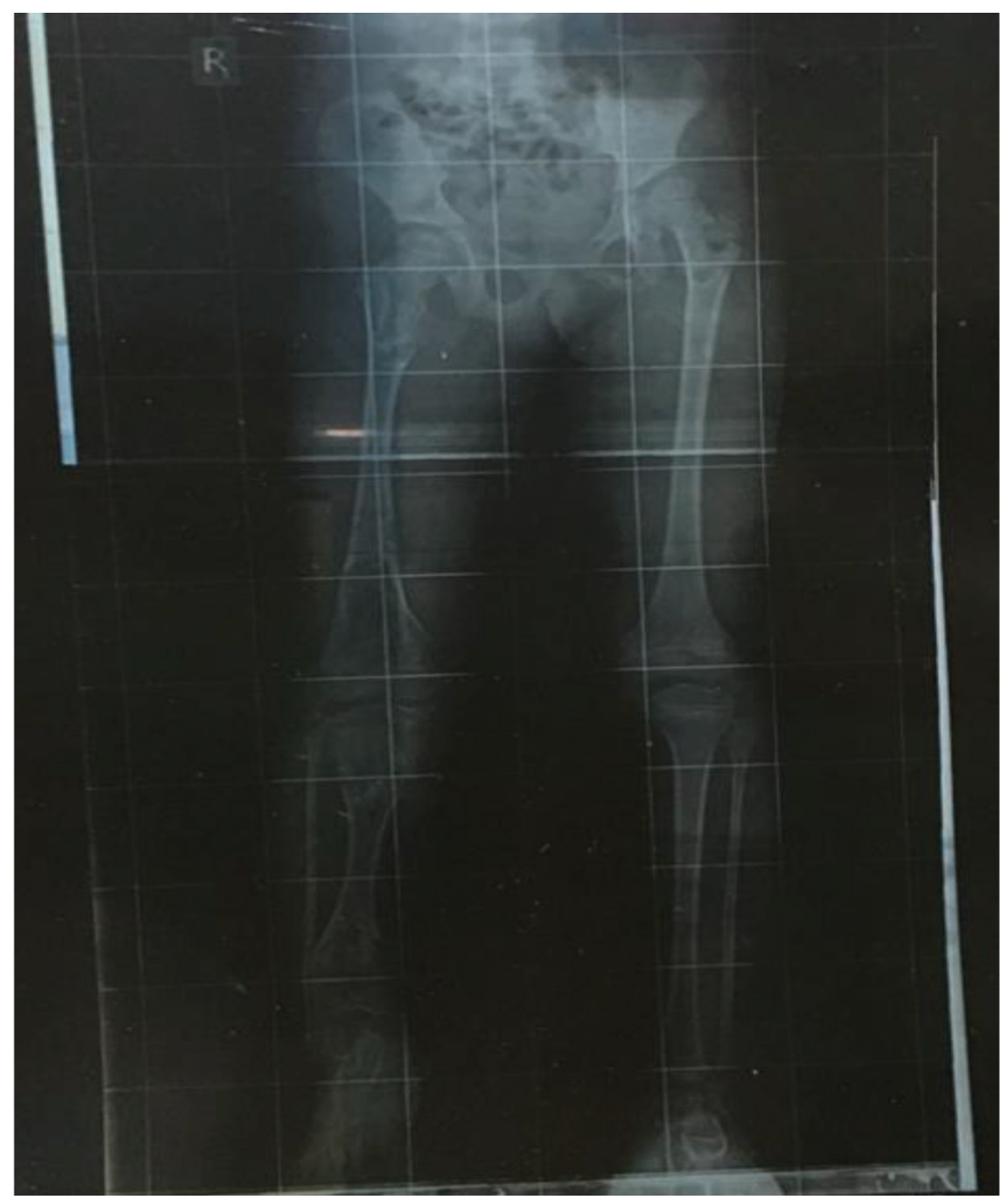

Figure 1. X Ray finding of Ollier Disease on lower limb dextra right foot, genu valgus of the knees, and keloid on the proximal and distal right leg were visible on the operated leg, no visible impairment were found on the non-operated leg.

In addition, the physical assessment was committed every day after the surgical intervention. Asymmetrical length of four centimeters was noticed after the true leg length tests on the both legs using plastic, retractable, and measurable tape. To observe the muscles strength of the tight, the manual muscle testing (MMT) was used by instructing the patient to lift up the both legs actively against gravity with the knee remained in neutral position, and the non-operated leg went first and followed by the operated leg. The MMT score for the non-operated and operated legs were 5 and 3 , respectively.

To evaluate the joint range of motions, the patient was asked to actively move the leg into the hip flexion, extension, abduction, adduction, internal rotation, and external rotation movements on nonoperated leg before the operated leg with the knee joint kept in the neutral position range of motions of the hip joints. Limited hip range of motion was found on the operated leg when compared with the non-operated demonstrated the muscles weakness in the tight muscles (flexion: $50^{\circ}$ vs. $120^{\circ}$; extension: $10^{\circ}$ vs. $15^{\circ}$; abduction: $20^{\circ}$ vs. $45^{\circ}$; adduction: $10^{\circ}$ vs. $45^{\circ}$; internal rotation: $20^{\circ}$ vs. $45^{\circ}$; external rotation: $20^{\circ}$ vs. $45^{\circ}$ ). For the knee joint, the passive range of motion tests were performed to evaluate the flexion and extension movements as regard the active range of motion test was unable to perform to avoid the irregular movement in the operated bones. The lower range of motion in the flexion and extension of the operated leg were recorded (flexion: $20^{\circ}$ vs. $140^{\circ}$; extension: $-5^{\circ}$ vs. $0^{\circ}$ ) with early end-feel of muscle spasm at the end of the than the non-operated leg. To measure the ankle joint range of motion, patient instructed to move the both ankle joints actively to the dorsal flexion and plantar flexion positions simultaneously, and it was found that there was restriction in the dorsal flexion position of $10^{\circ}$ between the operated and non-operated legs. All the range of motion tests were performed using 30$\mathrm{cm}$ length of goniometer. The patient was brought to out of the bed, and demonstrated of capability to control the static balance by standing on one leg more than 1 minutes with the hands were holding the edge of the bed.

The physical therapy management was set up to this case to improve the pain level, range of motion, muscles strength, bed mobilization, and prevent the bed rest complications while being treated in hospital. The intervention of physical therapy was giving to the patient followed of this 
course: Firstly, the patient was instructed seated on half lying position, to do free active exercise to the upper limbs for five minutes. In the same position, the patient received the passive range of motion exercise to the flexion and extension positions in knee joint and 20 seconds passive stretching to the gastrocnemius muscle repeated to four times to avoid the joint contracture and muscle shortening, respectively. Then, the active assisted range of motion exercise was performed by instructing the patient to flexion, adduction, abduction, internal rotation, and external rotation the hip joint actively as far as she can, with the knee positioned in the neutral position, and hands assisted by the physical therapist. For the ankle joint, the patient was instructed to move her ankle joint actively to the dorsal and plantar flexions position without any assisted by physical therapist, and advised to perform this exercise three times a day.

Further steps, the patient changed to the side lying position towards the non-operated leg to actively extension the operated leg. The patient instructed to do active range of motion exercises including flexion, adduction, abduction, internal rotation, and external rotation of the hip joint, flexion and extension of the knee joint, and dorsal and plantar flexions of the ankle joint actively for the non-operated leg. The repetition for the passive and active range of motion exercises was 10 times per set and repeated 2-3 sets. Patients were given isometric exercises by giving the hand resistant during the flexion and extension movements of elbow joints, and dorsal and plantar flexions movements of ankle joints eight seconds repeated for four times.

To prevent from the bed rest complication, the patient practiced the bed mobilization exercise including the body rolling to non-operated leg, sliding up and down, and moving to the edges of the bed for five minutes. The family member and patient were taught how to transfer the patient from the bed to the assisted tools such as wheelchair, walker, and crutches, also used those to the patient for standing and stepping exercises.

\section{Evaluation}

The physical therapy management seemed to had positive results after performed the physical assessments at the 3 days after intervention. The range of motion in the hip joint have improved from $5-10^{\circ}$ (flexion: $60^{\circ}$; extension: $15^{\circ}$; abduction: $30^{\circ}$; adduction: $20^{\circ}$; internal rotation: $30^{\circ}$; external rotation: $30^{\circ}$ ), while the MMT of the tight muscle was still remained the same, this probably because of the short duration of intervention program. For the knee range of motion, of $10^{\circ}$ improvement was observed in the flexion position and no improvement in extension position.

Ankle range of motion exercise during intervention program and self-exercise seemed to be effective to improve the ankle range of motion $10^{\circ}$ for the dorsal flexion. Moreover, the swelling on the operated-leg seemed to be controlled, although it was not possible to measure objectively because of the leg was wrapped by elastic bandage. The true leg length difference was remained the same. The patient was able to transfer from lying on the bed to standing with crutches and walking around the bed independently, and no wound that caused by bed rest complication was found.

\section{DISCUSSION}

This case report highlights that the patient with Ollier disease had undergone several surgeries, and at the recent surgery for enchondroma and bone lengthening in femur, received physical therapy management, which gave positive results for her movements and functional activities. From the previous reports also mentioned that surgery generally is the only treatment considered for this disorder, no observational or clinical trial studies on the physical therapy management following surgical intervention in OD patients have published. ${ }^{10}$

Our article has several limitations, such as: Firstly, OD presents itself under various clinical conditions that treated by different surgical techniques; Secondly, the physical therapy interventions demanding similar patient's disabilities; Thirdly, the short period of physical therapy management which could make the result invalid. This case study has shown that physical therapy management might benefit the disabilities following surgical intervention in OD, the same as the other orthopedic diseases.

Nevertheless, we did not follow-up on the patient's conditions because of the short period of clinical opportunity. During the clinical period, the patient has explained that she had to undergo the routine assessments and need to continue the exercise given by the physical therapist at home. But there was a report showed that a child patient with bone lengthening using Ilizarov had long term outcomes for the bone discrepancy in the lower limb, even with good supportive aids or without group-therapy, can improve the patient's satisfaction and functions in two-thirds of the cases at averages time of 17 years. ${ }^{11}$

Further surgical intervention will be then possible because she still has enchondromas in both of her arms. Since still there is less literacy of rehabilitation in Ollier's disease, the authors hope in the future there will be more rehabilitation 
studies published to share the clinical experience during physical therapy management. Moreover, it must be explained that it is very important to continuously follow-up on the effect of physical therapy management, even to evaluate the longterm outcomes.

\section{CONFLICT OF INTEREST}

No commercial party having an interest in the subject matter of this research will give a benefit on the authors or on any affiliation with which the authors are associated.

\section{ACKNOWLEDGEMENT}

The authors want to thank the Sanglah Hospital and Bachelor and Professional Program of Physical Therapy Udayana University, Bali, Indonesia for the clinical experience during internship program. This work received no funding from any institution.

\section{AUTHOR CONTRIBUTION}

IAMP conceived the study design and data collection and drafted the manuscript; IPGSA carried out the study design and drafting of the manuscript.

\section{REFERENCES:}

1. Schwartz HS, Zimmerman NB, Simon M, Wroble R, Millar E, Bonfiglio M. The malignant potential of enchondromatosis. The Journal of bone and joint surgery American volume. 1987;69(2):269-74.
2. Ollier M. De la dyschondroplasia. Bull Soc Chir Lyon. 1899;3:22-3.

3. de Mourgues G. Léopold Ollier, 1830-1900, the father of orthopedic surgery. Rev Chir Orthop Reparatrice Appar Mot. 1979;65:2.

4. Silve C, Jüppner H. Ollier disease. Orphanet J Rare Dis. 2006;1(1):37.

5. Mulder JD. Radiologic atlas of bone tumors: Elsevier; 1993.

6. McDermott A-L, Dutt S, Chavda S, Morgan D. Maffucci's syndrome: clinical and radiological features of a rare condition. The Journal of Laryngology \& Otology. 2001;115(10):845-7.

7. Akiyama M, Yamaoka M, Mikami-Terao Y, Ohyama W, Yokoi K, Arakawa Y, et al. Somatic mosaic mutations of IDH1 and NPM1 associated with cup-like acute myeloid leukemia in a patient with Maffucci syndrome. Int J Hematol. 2015;102(6):723-8.

8. Spranger J, Kemperdieck H, Bakowski H, Opitz J. Two peculiar types of enchondromatosis. Pediatr Radiol. 1978;7(4):215-9.

9. Amary MF, Damato S, Halai D, Eskandarpour M, Berisha F, Bonar F, et al. Ollier disease and Maffucci syndrome are caused by somatic mosaic mutations of IDH1 and IDH2. Nat Genet. 2011;43(12):1262-5.

10. Formis A, Allegri S, Posteraro L. Rehabilitation experience in a case of Ollier's disease. Acta Biomed. 2003;74(3):151-6.

11. Shahcheraghi GH, Javid M, Hadavi F. Pediatric lower limb Ilizarov lengthening with functional evaluation in adulthood: A report on underprivileged patients. journal of orthopaedics. 2015;12:S69-S74.

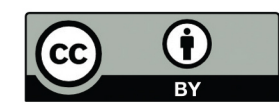

This work is licensed under a Creative Commons Attribution 